\title{
Small scale spatial heterogeneity of soil respiration in an old growth temperate deciduous forest
}

\author{
A. Jordan ${ }^{1,2}$, G. Jurasinski ${ }^{2}$, and S. Glatzel ${ }^{2}$ \\ ${ }^{1}$ Georg-August-University Goettingen, Department of Geography, Landscape Ecology-Unit, \\ Goldschmidtstrasse 5, 37077 Göttingen, Germany \\ ${ }^{2}$ University of Rostock, Faculty of Agricultural and Environmental Sciences, Landscape \\ Ecology and Site Evaluation, Justus-von-Liebig-Weg 6, 18059 Rostock, Germany \\ Received: 17 August 2009 - Accepted: 29 September 2009 - Published: 22 October 2009 \\ Correspondence to: A. Jordan (albrecht.jordan@gmx.de) \\ Published by Copernicus Publications on behalf of the European Geosciences Union.
}

9977

\section{Abstract}

The large scale spatial heterogeneity of soil respiration caused by differences in site conditions is quite well understood. However, comparably little is known about the micro scale heterogeneity within forest ecosystems on homogeneous soils. Forest age, 5 soil texture, topographic position, micro topography and stand structure may influence soil respiration considerably within short distance. In the present study within site spatial heterogeneity of soil respiration has been evaluated. To do so, an improvement of available techniques for interpolating soil respiration data via kriging was undertaken.

Soil respiration was measured with closed chambers biweekly from April 2005 to 10 April 2006 using a nested design (a set of stratified random plots, supplemented by 2 small and 2 large nested groupings) in an unmanaged, beech dominated old growth forest in Central Germany (Hainich, Thuringia). A second exclusive randomized design was established in August 2005 and continually sampled biweekly until July 2007.

The average soil respiration values from the random plots were standardized by

15 modeling soil respiration data at defined soil temperature and soil moisture values. By comparing sampling points as well as by comparing kriging results based on various sampling point densities, we found that the exclusion of local outliers was of great importance for the reliability of the estimated fluxes. Most of this information would have been missed without the nested groupings. The extrapolation results slightly improved when additional parameters like soil temperature and soil moisture were included in the extrapolation procedure. Semivariograms solely calculated from soil respiration data show a broad variety of autocorrelation distances (ranges) from a few centimeters up to a few tens of meters.

The combination of randomly distributed plots with nested groupings plus the in25 clusion of additional relevant parameters like soil temperature and soil moisture data permits an improved estimation of the range of soil respiration, which is a prerequisite for reliable interpolated maps of soil respiration. 


\section{Introduction}

Soil $\mathrm{CO}_{2}$ efflux is one of the largest carbon flux components. Globally it accounts for $20-40 \%(50-75 \mathrm{Gt} \mathrm{C} / \mathrm{yr})$ of the total annual input of carbon dioxide into the atmosphere (Houghton and Woodwell, 1989; Raich and Schlesinger, 1992; Schimel, 1995;

5 Lankreijer et al., 2003). Even small shifts between carbon release and photosynthetic uptake can have a significant influence on the atmospheric carbon budget (Pregitzer and Euskirchen, 2004).

4.1 bill hectares of land on earth are covered with boreal, temperate and tropical forests containing up to $80 \%$ of the terrestrial aboveground carbon and $40 \%$ of total 10 soil C (Dixon et al., 1994; Pregitzer and Euskirchen, 2004). However, mean soil efflux rates do not only vary between the major biome types, they also show high variability within the same biome and even within the same measurement site (Raich and Schlesinger, 1992). Thus, there are high uncertainties in the total annual values of site scale soil efflux rates (a site is understood here as a particular ecosystem e.g., a forest

15 or a wetland). Small-scale heterogeneities in soil efflux rates are, inter alia, caused by the high variability of soil structure (Bouma and Bryla, 2000), soil moisture (Davidson et al., 1998), bacterial and fungal communities (Gomoryova, 2004), root density (Hanson et al., 2000; Soe and Buchmann, 2005), soil organic matter content, wind speed at the soil surface and pressure patterns (Lankreijer et al., 2003; Martin and Bolstad, 20 2005).

Generally, the term "spatial heterogeneity" is used to refer to differences between measurement sites. Most of these sites are selected just because of their different sample characteristics, for example their different soil or vegetation type, stand structure or stand age (Law et al., 2001; Salimon et al., 2004; Vogel et al., 2005). Studies

25 describing within site "spatial heterogeneity", that means micro scale spatial heterogeneity within old growth forests with otherwise relatively homogeneous site conditions are extremely rare. Many studies in the past few years partitioned soil respiration into autotrophic and heterotrophic components (Kuzyakov, 2006; Subke et al., 2006) and

9979

advances have been made in understanding the dynamics of a wide range of soil $\mathrm{C}$ pools and their effects on soil respiration (Baggs, 2006; Kalbitz et al., 2000; Ryan and Law, 2005). However, it still remains unclear on which scales factors influencing soil respiration vary, while influencing total soil respiration rate.

5 Having said this, it is very likely that these factors do not take effect on the same scales within a given site. Thus, an approach spanning various spatial scales seems to be adequate. Therefore, in the present study we adopted a three-fold strategy. First, we set up nested groups of sampling plots. Second, we recorded data from stratified randomly distributed plots. Third, additional information gathered at the sampling points was used via kriging to improve the reliability of the site scale estimates of soil efflux rates. With this approach we aimed for a better understanding of the spatial variability of soil respiration in old growth temperate deciduous forests. Specifically we tested the following hypotheses:

1) The environmental controls for soil respiration vary on different spatial scales within forest sites. Therefore, a multiple scale sampling approach improves the reliability of site scale soil efflux rate estimates extrapolated from point measurements.

2) The consideration of additional parameters with control potential for soil respiration further improves the extrapolation results.

\section{Material and methods}

\subsection{Site}

The study site is located in the core zone of the Hainich National Park in Thuringia, Central Germany $\left(51^{\circ} 04^{\prime} 46^{\prime \prime} \mathrm{N}, 10^{\circ} 27^{\prime} 08^{\prime \prime} \mathrm{E}, 440 \mathrm{~m}\right.$ a.s.I.). Sampling locations were established within the fetch area of an Eddy Covariance Tower that is run by the MPI for Biogeochemistry Jena, Germany. The mean annual temperature and precipitation 
are $6-7^{\circ} \mathrm{C}$ and $750 \mathrm{~mm}$. Soils are chromic cambisols (ISSS, 1998) on limestone. Vegetation structure is that of an old growth forest with a large amount of dead wood and high species diversity. The oldest trees reach $250 \mathrm{yr}$ of age. The forest is dominated by Fagus sylvatica L. Additionally Fraxinus excelsior L., Acer pseudoplatanus L., and

5 Acer platanoides L. occur in smaller fractions.

\subsection{Sampling design}

We implemented two different sampling approaches. On the one hand we followed a double nested, stratified random approach (nested series) to determine the maximum range of autocorrelation as a prerequisite for extrapolation (Fig. 1). 79 measurement

10 locations (called "plots" in the following) were arranged in this series. We superimposed a grid on a map of the site that divides it into 43 rectangular cells with an edge length of $34 \mathrm{~m}$. In each of the grid cells one plot was placed in a random location to reduce the maximum distance between the points and to avoid large gaps between them. Thus, 43 plots were distributed in a stratified random layout across the whole study site. To

15 obtain spatially nested plots 2 cells were chosen randomly from the grid and 36 plots were placed in 4 groups within them resulting in two small and two larger plot groupings nested within each other (see Fig. 1 for details). This double nested approach allowed computing soil respiration data with three different spatial resolutions. Additionally 81 plots were located completely random across the study site (random series).

20 All plots were equipped with PVC collars with an inner diameter of $10 \mathrm{~cm}$ and a height of $7 \mathrm{~cm}$. They were inserted $3 \mathrm{~cm}$ into the soil two weeks before the measurements started to avoid disturbance. Each collar was laterally fixed with three tent pegs to secure fix them against removal by animals.

\subsection{Sampling procedure}

25 Both series were sampled biweekly. For the nested series sampling was carried out from April 2005 to April 2006. The random series was sampled from August 2005 to

9981

June 2007. During the time when both series were sampled (August 2005 to April 2006) the biweekly sampling was carried out alternately.

Soil respiration was recorded with a portable infrared gas analyser (IRGA, EGM-4) connected to a closed soil respiration chamber (SRC-1), both devices by PP Systems,

5 Hitchin, UK. The soil respiration rate was calculated as the rate of change in $\mathrm{CO}_{2}$ concentration within the chamber headspace. The EGM-4 allows for an automatic calculation of emission rates provided that the volume of the chamber and the surface area of the soil are set. The $\mathrm{CO}_{2}$ concentration was monitored each $4.8 \mathrm{~s}$ over an interval of $124 \mathrm{~s}$. Only the final results were saved and recorded.

10 In preparation of both measurement series, a set of comparative measurements was performed using a second soil respiration measurement device (Li-cor 6400-09, Licor, Inc., Lincoln, Nebraska, USA), to ensure the quality of the recorded data. Due to the high reproducibility and the stability of both measurement results, the EGM-4 measurements were seen as reliable and sufficient.

15 In addition to the recording of respiration rates soil temperature was measured next to each plot at a depth of $0-10 \mathrm{~cm}$ below the litter layer by digital precision thermometers (Greisinger, Regenstauf, Germany for the nested series; Testo, Lenzkirch, Germany for the random series). Due to the year round measurement campaigns, a few data gaps occurred at ground frost events. These were closed with data from the

20 continuously measuring soil sensors of the Max-Planck-Institute for Biogeochemistry, Jena. These sensors collect data at depths of $-2,-5,-15,-30$ and $-50 \mathrm{~cm}$. To assure comparability, the average temperature of the sensors in the depths of -2 and $-5 \mathrm{~cm}$ were calculated. These values showed a very close and significant correlation with the average value of the own measurements at non-ground frost days.

From the 14 April 2005 until the 12 April 2006 soil moisture was determined gravimetrically. During each measurement event, gravimetric soil water content was determined next to each plot. Therefore soil samples were taken twice at each plot with a small auger up to a depth of $-15 \mathrm{~cm}$. These wet samples were weighted, oven-dried for $24 \mathrm{~h}$ at $105^{\circ} \mathrm{C}$ to stable weight and weighted again. The soil moisture was calculated as the 
percentage difference between wet and dry weight. From April 2006 until the end of the measurements soil moisture was determined with frequency domain reflectrometry (fdr) at 0-6 cm soil depth below the litter layer with the ThetaProbe Soil Moisture Sensor - ML-2x and the Soil Moisture Meter - HH2 (AT-Delta-T Devices Ltd., Cambridge,

5 UK). In contrast to soil temperature, data gaps during ground frost periods could not be closed using data from the eddy covariance tower, because of the large spatial variability of soil moisture measurements at single measurement dates.

\subsection{Statistics}

Tests for normal distribution with the Kolmogoroff-Smirnoff testing algorithm showed 10 that non-parametric testing procedures were necessary, so we proceeded with Spearman rank correlations. All statistical calculations were carried out with STATISTICA 7.0 (Statsoft, Oklahoma, USA).

To estimate the dependency of seasonal variation of soil respiration from soil temperature, the temperature functions were fitted by regression to the simple exponential 15 equation:

$R=k e^{a T}$

with $R=$ soil respiration $\left[\mathrm{g} \mathrm{CO}_{2} \mathrm{~m}^{-2} \mathrm{a}^{-1}\right], T=$ soil temperature $(0-10 \mathrm{~cm})\left[{ }^{\circ} \mathrm{C}\right], k$ and $a$ are constants (Davidson et al., 1998; Knohl et al., 2008). $Q_{10}$ represents the temperature response of soil respiration and is calculated with the simple formula:

${ }_{20} Q_{10}=e^{a 10}$

Saiz et al. (2006) and Stoyan et al. (2000) found that soil moisture is more important for the determination of spatial effects in temperate deciduous forests than soil temperature. Therefore, we consider soil moisture in the model (Eq. 3).

$R=k e^{a T} e^{b \theta}, \quad$ or $\quad \ln (R)=\ln (k)+a(t)+b(\theta)$

9983

with $\theta=$ soil moisture measured at $0-6 \mathrm{~cm}[\mathrm{vol} \%]$ and $a, b$ are fitted constant. The exponential equation taken from Knohl et al. (2008), was log-transformed to a linear model in order to conduct linear regression for the estimation of the parameters. Soil respiration rates were standardized using soil moisture and soil temperature. Eq. 4 5 presents the modified version of Eq. (3), where $R_{\delta_{T} \delta_{\theta}}$ represents the modelled soil respiration for each collar, $T$ and $\theta$ are the standardized soil temperature and soil moisture. $\delta_{T}$ and $\delta_{\theta}$ are the differences between standardized and measured temperature and moisture values and $k, a$ and $b$ are constants again.

$$
\begin{aligned}
R_{\delta_{T} \delta_{\theta}} & =k e^{a\left(T+\delta_{T}\right)} e^{b\left(\theta+\delta_{\theta}\right)} \\
& =k e^{a T} e^{a \delta_{T}} e^{b \theta} e^{b \delta_{\theta}} \\
& =R e^{a \delta_{T}} e^{b \delta_{\theta}} \\
R_{\text {standard }} & =\frac{R_{\delta_{T} \delta_{\theta}}}{e^{a \delta_{T}} e^{b \delta_{\theta}}}
\end{aligned}
$$

Equation (4) can be transformed to separate $R$, so $R$ is replaced by $R_{\text {standard }}$ (Eq. 5). The modelled $R_{\delta_{T} \delta_{\theta}}$ term in Eq. (5) can be substituted by the measured soil respiration 15 values. We used the trend identification tool of ArcGIS 9.2 to identify spatial trends by plotting single soil respiration measurement events within a three dimensional diagram. To estimate the confidence of the observed total mean flux, we calculated $N$, the number of measurement locations needed for a given precision level (Davidson et al., 2002; Yim et al., 2003; Adachi et al., 2005; Knohl et al., 2008) using Eq. (6):

${ }_{20} N=\left[\frac{t_{\alpha} \times s}{\text { range } / 2}\right]^{2}$,

with $t$ the Student's t-statistic, $s$ the standard deviation of one set of daily measurements, and range the desired interval around the daily mean. $N$ was calculated for each measurement date separately. $N$ was averaged to obtain a valid $N$ for the entire study. 


\subsection{Geostatistical analysis}

We extrapolated the pointwise measurements using ordinary kriging. Kriging is based on the construction of experimental semivariograms from the data (Goovaerts, 1999; Webster and Oliver, 2001). To optimize the kriging results we varied the lag distance

5 until we obtained the best possible parameter estimates. Kriging was carried out using the Geostatistical Analyst extension of ArcGIS 9.2 (ESRI, Redlands, USA).

We used all sampling points located within the two grid cells with the nested groupings to quantify autocorrelation at different spatial scale. Thus, we used three different sets of plots for estimating the kriging parameters. First, only the stratified random plots

10 of the nested series with relatively large inter-plot distances were used. Then, the data of the larger groupings from the nested series and finally the data of the small scale groupings were added. The maps as well as the parameter estimates resulting from ordinary kriging with these three datasets were compared (Fig. 6). The cell size of the maps was set to $10 \times 10 \mathrm{~cm}$ and the maps were classified in $0.01 \mathrm{~g} \mathrm{CO}_{2} \mathrm{~m}^{-2} \mathrm{~h}^{-1}$ units,

15 the same resolution as the applied measurement equipment. "Hawth's Analysis Tool" (http://www.spatialecology.com, extension to ArcGIS) was used to count the number of equal values per class. Thus, average soil respiration rates were calculated for different sampling densities.

To estimate annual fluxes based on the random series with 81 data points, regres20 sion equations using measured soil respiration, soil moisture and soil temperature data were calculated for each plot. Soil temperature values measured at the eddy covariance facility were used to estimate the mean flux for each plot each day of the year. Two methods were used for further calculation: On the on hand we calculated the final annual flux of the site from the average sum of all plots, on the other hand we used

25 a geostatistical approach. Therefore average standardised soil respiration values of each plot were extrapolated using ordinary kriging. A minimum convex polygon was created around the measurement points and reduced by $10 \mathrm{~m}$ inwards to avoid border effects. The resulting polygon was used to clip the ordinary kriging result. Zonal

9985

statistics were performed to calculate the total soil respiration rate at the study site.

\section{Results}

\subsection{Seasonal variation of soil respiration}

Looking solely at the flux rates of the random series the measurements started 5 with average soil respiration rates of $0.48 \mathrm{~g} \mathrm{CO}_{2} \times \mathrm{m}^{-2} \times \mathrm{h}^{-1}$, with a soil temperature of $14^{\circ} \mathrm{C}$ and a soil moisture of $40 \%$ (Fig. 2). From September 2005 the average soil respiration rate decreased constantly until it reached an absolute minimum of $0.04 \mathrm{~g} \mathrm{CO}_{2} \times \mathrm{m}^{-2} \times \mathrm{h}^{-1}$ in January 2006. Then, in spring 2006, the soil temperature increased rapidly. This was followed with a little delay by the soil respiration rate. The

10 two lower respiration values in the middle of May and July 2006 seem to correspond with temporal decreases in soil moisture availability. Maximum soil temperature and minimum soil moisture was measured on 26 July 2006.

The seasonal variation of soil respiration is clearly temperature dependent (Fig. 3, $r^{2}=0.69, Q_{10}=2.3$ ). $Q_{10}$ amounts to 3.9. The total average soil respiration value is

$150.28 \mathrm{~g} \mathrm{CO}_{2} \mathrm{~m}^{-2} \mathrm{~h}^{-1}$. However, the relation between soil respiration and soil temperature was much closer at collars with lower soil moisture content $\left(0-30 \%\right.$ Vol., $r^{2}=0.69$, $\left.Q_{10}=2.3\right)$ compared to wetter plots $\left(>60-90 \%\right.$ Vol., $\left.r^{2}=0.32, Q_{10}=4.1\right)$. The highest average respiration rates $\left(0.30 \mathrm{~g} \mathrm{CO}_{2} \mathrm{~m}^{-2} \mathrm{~h}^{-1}\right)$ were observed at medium soil moisture between >30-60 [\% Vol.].

20 Soil temperature did not vary much in space (average soil temperature variability at a given measurement date was $1.3^{\circ} \mathrm{C}$ ), whereas soil moisture measurements showed a considerable spatial heterogeneity as well as high seasonal variability. Total average volumetric water content was $37 \%$ with a wide range from $5 \%$ to $88 \%$. A multiple regression model including soil moisture and soil temperature as explanatory variables

25 slightly improves the explanation $\left(R^{2}\right.$ increased from 0.60 to 0.63$)$. This model was used for the regionalization. 


\subsection{Spatial distribution}

\subsubsection{Spatial trends}

When averaged in time, soil respiration does not show a spatial trend, because the presence and absence of soil respiration hotspots does not follow a regular pattern.

5 Therefore, ordinary kriging can be carried out without problems.

\subsubsection{Number of measurement plots required}

There are few but highly significant outliers regarding annual soil respiration rates even within short distances. This underlines the need to calculate the number of measurement points required for different levels of accuracy beforehand. Measurements from

$106 \pm 4$ locations are necessary for an $80 \%$ confidence level with an error limit of $30 \%$ around the full population mean (Table 1). Higher levels of precision require a higher number of measurement locations. At a $95 \%$ confidence level, $16 \pm 11$ collars are necessary for the same large error limit. Reducing this limit to $20 \%$ precision increases the required number of collars up to $35 \pm 26$, further precision can be achieved by using $15140 \pm 103$ at an error limit of $10 \%$.

\subsubsection{Kriging preparation}

Data point density was varied within two grid cells to infer the appropriate parameters for kriging (Fig. 4). Whereas the calculated average soil respiration rates in one of the grid cells changed little at different sampling densities, soil respiration rates decreased

20 significantly with higher numbers of collars within the other. Both cells are characterized by artificial block structures at low and medium sampling point density, indicating a distance between the sampling points wider than the range of the semivariograms. Much of the block structures can be smoothed by using a coarser scale for soil respiration, but not all.

9987

\subsubsection{Semivariograms}

Varying lag distances when calculating semivariograms resulted in markedly heterogeneous autocorrelation ranges. When using a lag distance of $10 \mathrm{~m}$ the resulting semivariograms reveal a lack of spatial autocorrelation (Fig. 5a, b). Zooming in by choosing

5 smaller lag sizes (Fig. 5c,d) whilst reducing the dataset by eliminating outliers, results in small range autocorrelation. Furthermore, ranges vary considerably from date to date. However, the average range of autocorrelation was determined at $9 \mathrm{~m}$, using lag sizes of $2 \mathrm{~m}$. This lag size was used in all further steps of analysis.

\subsubsection{Maps of soil respiration}

10 Maps of soil respiration rates were extrapolated based on ordinary kriging. On the one hand data from the nested series was used (Fig. 6a). The resulting map exhibits a high level of uncertainty due to the short range of the calculated semivariogram $(<20 \mathrm{~m})$ and the low sampling point density within the study site with distances between adjacent collars $>25 \mathrm{~m}$ (except within the observational windows). Even at class sizes

15 of $0.03 \mathrm{~g} \mathrm{CO}_{2} \mathrm{~m}^{-2} \mathrm{~h}^{-1}$ the map has many block structures. The corresponding map of predicted standard errors shows concentric rings around single measurement collars with low standard error and great areas with high standard errors outside the range of the calculated semivariogram (Fig. 6b). The negative mean error indicates that the interpolated soil respiration data are slightly overestimated by the model. On the other 20 hand data from the random series was used for interpolation (Fig. 6c). Due to the higher measurement point density, the predicted standard error map is much smoother compared to results based on the nested series data (Fig. 6d).

A further interpolation run is based on random series and standardized soil respiration rates (Fig. 6e). To achieve standardized soil respiration rates average soil respira25 tion was used with Eq. (5). For the 2006 series it amounts to $0.26 \mathrm{~g} \mathrm{CO}_{2} \mathrm{~m}^{-2} \mathrm{~h}^{-1}$ and a typical soil temperature of $11.6^{\circ} \mathrm{C}$ results. This is much higher than the total average soil temperature and caused by the exponential dependence between soil tempera- 
ture and soil respiration. The corresponding soil moisture value was determined using the regression function between soil temperature and soil moisture. Standardization causes the interval of soil respiration to shrink to $0.15-0.23 \mathrm{~g} \mathrm{CO}_{2} \mathrm{~m}^{-2} \mathrm{~h}^{-1}$. The predicted standard error as well as the RMSE are smaller compared to the interpolation

5 based on average soil respiration alone (Fig. 6f). Comparing the maps of average and standardized soil respiration reveals the influence of soil temperature and soil moisture. Whereas soil temperature is mainly evenly distributed, the map predominantly shows the distribution of soil moisture deficits or excessive supply which impedes soil respiration.

The annual flux calculated solely from 81 data points of the random series yielded a soil respiration rate of $2285.5 \mathrm{~g} \mathrm{CO}_{2} \mathrm{~m}^{-2} \mathrm{a}^{-1}\left( \pm 480.2 \mathrm{~g} \mathrm{CO}_{2} \mathrm{~m}^{-2} \mathrm{a}^{-1}\right)$ or $6.23 \mathrm{MgCha}^{-1} \mathrm{a}^{-1}\left( \pm 1.31 \mathrm{MgCha}^{-1} \mathrm{a}^{-1}\right)$ in 2006 and can be trusted at a confidence level of $90 \%$ within an error limit of $10 \%$ (or $99 \%$ confidence level at an error limit of $20 \%$ ). Using the geostatistical approach accounting for the spatial distribution of the 15 plots yielded a soil respiration rate of $1875.5 \mathrm{~g} \mathrm{CO}_{2} \mathrm{~m}^{-2} \mathrm{a}^{-1}$ or $5.11 \mathrm{MgCha}^{-1} \mathrm{a}^{-1}$ in 2006.

\section{Discussion}

Considerable spatial heterogeneity of soil respiration rates was apparent within our study site due to a variety of confounding factors:

20 Soil temperature is an important control for the seasonal variation of soil respiration (Davidson et al., 1998; Janssens and Pilegaard, 2003; Reichstein et al., 2008). Reichstein et al. (2008) describe a variety of models reflecting a nonlinear positive relationship between soil respiration and soil temperature. Here, we used the $Q_{10}$ function (van't Hoff, 1898). It is widely accepted and often used (Janssens and Pilegaard, 2003;

25 Hashimoto, 2005; Pavelka et al., 2007). However, it must be accepted that the $Q_{10}$ function integrates several controls: An increase in soil temperature influences many biological and physiochemical processes e.g. root biomass distribution, litter inputs and 9989

the activity of microbial populations (Janssens and Pilegaard, 2003). However, the calculated $Q_{10}$-value of 3.9 fits well within the range of other published data of temperate deciduous forests (Raich and Schlesinger, 1992; Davidson et al., 1998; Janssens and Pilegaard, 2003; van Miegroet et al., 2007). The relationship between soil temperature 5 and soil respiration was much closer at dry conditions $\left(r^{2}=0.69, Q_{10}=4.1\right)$ compared to wet conditions $\left(r^{2}=0.32, Q_{10}=2.3\right)$. This is in contradiction to results by Janssens et al. (2003). They also found that $Q_{10}$ is not constant during the year, while interpreting data from a Danish beech forest. However, they observed the lowest $Q_{10}$ values in early autumn during a period of drought stress when soil respiration was completely

10 unrelated to soil temperature and the highest values in winter. Very low or very high soil water contents may limit soil respiration (e.g., Davidson et al., 1998; Reichstein and Beer, 2008; Sotta et al. 2006). In our data-set we did not experience drought. Instead, high soil moisture values occurred at all seasons. This might be due to pockets of high clay content (Knohl et al., 2008) with increased soil moisture. Taking this into consid-

15 eration, the low $Q_{10}$ value in our study is more likely caused by the characteristics of a few collars throughout the entire year than a characteristic of seasonality. We find no considerable relationship between soil moisture and soil respiration. That might be caused by the relatively low number of potentially impeding situations (drought or high soil moisture) as also found by Knohl et al. (2008) in the same study area.

\section{$20 \quad 4.1$ Spatial heterogeneity of soil respiration}

Soil respiration as well as soil moisture did not show any spatial trends. However, soil respiration rates and soil moisture revealed a patchy pattern without any obvious structures. The spatial variability of soil temperature apparently does not drive this heterogeneity because it is very small (less than $\pm 1{ }^{\circ} \mathrm{C}$ during a single measurement

25 day). This is in line with Yim et al. (2003) who report that soil temperature is not a dominant factor for the spatial variability of soil respiration in temperate broadleaved forests.

However, combining soil temperature and soil moisture effects within a single expo- 
nential equation slightly enhances the predictability of soil respiration measurements $\left(r^{2}=0.63\right.$ compared to $\left.r^{2}=0.61\right)$. But the effect was not as pronounced as described by Knohl et al. (2008) for the same study site. Nevertheless, we used Eq. (5) to calculate standardized soil respiration measurement values for defined averaged parameters to

5 achieve a higher level of accuracy.

Due to the relatively smaller coefficient of variation of $\mathrm{CO}_{2}$ flux in the field compared with $\mathrm{N}_{2} \mathrm{O}$ fluxes, generally less attention has been paid to the spatial heterogeneity of $\mathrm{CO}_{2}$ fluxes (Ishizuka et al., 2005). A wide variety of authors performed statistical analyses based on the Student's t-distribution to calculate the number of measure-

10 ment locations required for an adequate level of precision (Folorunso and Rolston, 1984; Davidson et al., 2002; Yim et al., 2003; Adachi et al., 2005; Knohl et al., 2008). According to our calculations a higher number of plots is demanded to achieve a sufficient level of precision compared to published studies within temperate deciduous broadleaved forest. Especially the differences to the results of Knohl et al. (2008)

15 are remarkable, because they performed their analysis within the same research area. $\mathrm{Knohl}$ et al. used data from 10 different studies within the same research site, but most of these measurements were performed using much less sampling points, within smaller observational windows and only during the vegetation period. This suggests that either there sampling density was insufficient, or - and more likely - that spatial

20 heterogeneity is increasing when all-season measurements are considered. This has important implications for the geospatial interpolation.

Soe and Buchmann (2005), also working in the Hainich National Park, observed that trees have a stronger stabilizing effect on patterns of soil respiration than understory vegetation within an annual perspective. If the summer or winter season were considered alone, the variation in soil respiration was much higher (ibid.). Soil respiration was higher in areas with high mean dbh, compared to areas with many small trees. No correlation was found between the distance to the nearest trees and soil respiration, but they determined a negative correlation between the number of tree species and soil respiration.

9991

In contrast to Soe and Buchmann (2005), who worked in an old growth forest, Saiz et al. (2006) found significantly higher soil respiration rates in close vicinity to tree stems for the younger stands, which may be explained by the more uneven distribution of roots in the young forests (Saiz et al., 2006). Shibistova et al. (2002) determined 5 significantly lower efflux rates in small forest gaps in a boreal forest, caused by recurring fire events which led to the total absence of higher plants. Khomik et al. (2006) showed that spatial variability is driven by seasonal respiratory activities of roots in a $74 \mathrm{yr}$ old stand in Ontario. This could be an explanation for the limited spatial variability of efflux rates during winter. Furthermore, broadleaved deciduous trees showed a $15 \%$ higher - respiration rate than evergreen coniferous species, whereas this difference was not always significant (Khomik et al., 2006).

\subsection{Optimizing the parameters for interpolation}

The influence of different sample sizes was assessed using nested groupings of plots that are arranged in two of the grid cells. Huge differences between the average soil

15 respiration rates of different sampling densities can be caused by single outliers outside the considered grid cells. This led us to vary the lag distances and bin sizes when calculating the semivariograms (Franklin and Mills, 2003). The observed range sizes clearly depend on the selected bin sizes. Large lag sizes $(>10 \mathrm{~m})$ sometimes correspond with large range sizes indicating that some drivers of soil respiration may

20 vary on coarser scales than others. For this study, small bin sizes were selected to determine autocorrelation at small ranges where large bin sizes did not indicate any autocorrelation, and small bin sizes were selected to consider even large variability between locations close together. However, the calculated ranges of autocorrelation also varied considerably between measurement dates. This may be caused by fluctuations

25 in spatial patterns due to changes in microbial activity, organic matter input or root activity during the course of the year (Saiz et al., 2006). The then determined average range of the semivariograms $(9 \mathrm{~m})$ is comparable to ranges found in investigations at the same study site with a range of $6 \mathrm{~m}$ (Soe and Buchmann, 2005) and in other stud- 
ies (e.g., $10 \mathrm{~m}$ in Ishizuka et al., 2005). The increased amount of plots of the random series (81) compared to the stratified random plots (43) reduces the average distances and considerably enhances the validity of the kriging result proved by the associated predicted standard error map (Fig. 6d). The predicted standard error decreased from $50.07 \mathrm{~g} \mathrm{CO}_{2} \mathrm{~m}^{-2} \mathrm{~h}^{-1}$ to $0.05 \mathrm{~g} \mathrm{CO}_{2} \mathrm{~m}^{-2} \mathrm{~h}^{-1}$ (at average respiration rates of 0.27 , respectively $0.26 \mathrm{~g} \mathrm{CO}_{2} \mathrm{~m}^{-2} \mathrm{~h}^{-1}$ ). This results because the average distances between the plots of the random series better fit to the calculated range of the semivariogram than to the stratified random series.

Single hotspot soil respiration events can adulterate not only the semivariograms but

10 also large areas within the interpolated maps especially when the sampling density is small. The results of our nested approach measurements clearly show the misleading effect of single outliers (Fig. 4). Therefore, their elimination is important for the reliability of the interpolation results, even when the local hot spot measurement may be functionally justified. This was also supported by the estimation of an adequate number of

15 collars based on the Student's t-distribution required for an adequate level of precision, which is widely used in previous studies (Folorunso and Rolston, 1984; Davidson et al., 2002; Yim et al., 2003; Adachi et al., 2005; Knohl et al., 2008).

Another important factor regarding the semivariogram calculation might be the area covered by the closed chamber used for respiration measurement. Because a larger

20 variation in emitted gas is covered with larger chambers these may require fewer sampling points compared to small chambers where the variation within one chamber is much smaller (Yim et al., 2003). The chamber used in the present study has an area of $78 \mathrm{~cm}^{2}$, which is comparably small. However, with even smaller soil cores covering an area of $1.8 \mathrm{~cm}^{2}$ Robertson et al. (1997) and Stoyan et al (2000) found autocorrelation distances of less than $30 \mathrm{~cm}$. Seen in relation to our results a possible influence of the chamber size becomes obvious.

9993

\subsection{Interpolated maps}

To avoid the influence of seasonal effects we based the kriging on mean annual soil respiration rates. Ordinary kriging was preferred to cokriging because of the bivalent nature of the supporting parameters (Pringle and Lark, 2006). Soil temperature 5 primarily accounts for seasonal changes and did not show any spatial heterogeneity. Therefore, it is a poor predictor for spatial interpolation (Yim et al., 2003). Soil moisture varies on the seasonal scale as well as on the spatial scale and the values show little autocorrelation. Therefore, the proposed approach to standardize soil respiration using defined soil moisture and temperature values seems to be more promising compared

10 to cokriging. This should not be seen as contradictory to coregionalisation attempts. A particular model may reproduce the components of variation better at some spatial scales than it does at others (Pringle and Lark, 2006). Thus, cokriging methods may be the best choice when parameters with a better autocorrelation structure are available. But in the case of complicated autocorrelation situations like in the presented data, the 15 standardization approach might yield better results.

\subsection{The standardisation approach}

The standardisation of soil respiration using soil temperature and soil moisture largely reduces the interpolated spatial heterogeneity of soil respiration. The remaining heterogeneity must therefore be caused by other, not measured variables. As a result, the interpolation of soil respiration data requires large sampling densities if better, spatially autocorrelated parameters than soil moisture and soil temperature are not available. Standardizing of soil respiration can help to minimize artifacts caused by temporal and spatial small scale heterogeneity of soil moisture and soil temperature. However, to further increase the reliability of the interpolation it would be necessary to incorporate 25 other parameters with less temporal variability and larger autocorrelation ranges.

In summary, the geostatistical approach yielded slightly lower results than the statistical approach, which indicates that the calculated fluxes of even a high number of 
measurement plots can be further improved by involving spatial parameter.

\section{Conclusions}

This study concentrates on the plot scale spatial effects, the relationships and confounding co-variations between soil temperature and soil moisture. Variations on the

5 micro scale as well as at larger scales have to be considered whenever plot scale variations are influenced (Reichstein and Beer, 2008). We conclude that only a combination of a randomized and a double nested sampling approach as well as the appropriate incorporation of additional parameters like soil temperature and soil moisture data may permit a sufficient estimation of the range of soil respiration, which is a prerequisite for reliable maps of soil respiration based on interpolation. Appropriate range distances should always govern the sampling design. Therefore, there is a need to estimate the range distance based on extensive pre-studies with nested measurement locations. Furthermore, our results show that the consideration of seasonal controls facilitates the interpolation of soil respiration measurements.

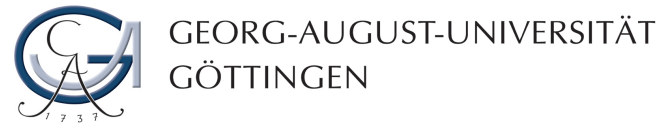

This Open Access Publication is funded by the University of Göttingen.

\section{References}

Adachi, M., Bekku, Y. S., Konuma, A., Kadir, W. R., Okuda, T., and Koizumi, H.: Required sample size for estimating soil respiration rates in large areas of two tropical forests and of two types of plantation in Malaysia, Forest Ecol. Manag., 210, 455-459, 2005.

\section{5}

Baggs, E. M.: Partitioning the components of soil respiration: a research challenge, Plant Soil, 284, 1-5, 2006

Bouma, T. J. and Bryla, D. R.: On the assessment of root and soil respiration for soils of different textures: interactions with soil moisture contents and soil $\mathrm{CO}_{2}$ concentrations, Plant Soil, 227, 215-221, 2000.

Davidson, E. A., Belk, E., and Boone, R. D.: Soil water content and temperature as independent or confounded factors controlling soil respiration in a temperate mixed hardwood forest, Glob. Change Biol., 4, 217-227, 1998.

Davidson, E. A., Savage, K., Verchot, L. V., and Navarro, R.: Minimizing artifacts and biases in chamber-based measurements of soil respiration, Agr. Forest Meteorol., 113, 21-37, 2002.

Dixon, R. K., Brown, S., Houghton, R. A., Solomon, A. M., Trexler, M. C., and Wisniewski, J.: Carbon pools and flux of global forest ecosystems, Science, 263, 185-190, 1994.

Folorunso, O. A. and Rolston, D. E.: Spatial variability of field-measured denitrification gas fluxes, Soil Sci. Soc. Am. J., 48, 1214-1219, 1984.

15 Franklin, R. B. and Mills, A. L.: Multi-scale variation in spatial heterogeneity for microbial community structure in an eastern Virginia agricultural field, Fems Microbiol. Ecol., 44, 335-346, 2003.

Gomoryova, E.: Small-scale variation of microbial activities in a forest soil under a beech (Fagus sylvatica L.) stand, Pol. J. Ecol., 52, 311-321, 2004.

20 Goovaerts, P.: Geostatistics in soil science: state-of-the-art and perspectives, Geoderma, 89, 1-45, 1999.

Hanson, J., Edwards, N. T., Garten, C. T., and Andrews, J. A.: Separating root and soil microbial contributions to soil respiration: a review of methods and observations, Biogeochemistry, 48, 115-146, 2000.

25 Hashimoto, S.: $Q_{10}$ values of soil respiration in Japanese forests, J. Forest Res.-Jpn., 10, 409413, 2005.

Houghton, R. A. and Woodwell, G. M.: Global climatic-change, Sci. Am., 260, 36-44, 1989.

Ishizuka, S., Iswandi, A., Nakajima, Y., Yonemura, L., Sudo, S., Tsuruta, H., and Muriyarso, D.: Spatial patterns of greenhouse gas emission in a tropical rainforest in Indonesia, Nutr. Cycl. Agroecosys., 71, 55-62, 2005.

Janssens, I. A. and Pilegaard, K.: Large seasonal changes in $Q_{10}$ of soil respiration in a beech forest, Glob. Change Biol., 9, 911-918, 2003.

Kalbitz, K., Solinger, S., Park, J. H., Michalzik, B., and Matzner, E.: Controls on the dynamics 
of dissolved organic matter in soils: a review, Soil Sci., 165, 277-304, 2000

Khomik, M., Arain, M. A., and McCaughey, J. H.: Temporal and spatial variability of soil respiration in a boreal mixedwood forest, Agr. Forest Meteorol., 140, 244-256, 2006.

Knohl, A., Soe, A. R. B., Kutsch, W. L., Gockede, M., and Buchmann, N.: Representative

5 estimates of soil and ecosystem respiration in an old beech forest, Plant Soil, 302, 189-202, 2008.

Kuzyakov, Y.: Sources of $\mathrm{CO}_{2}$ efflux from soil and review of partitioning methods, Soil Biol. Biochem., 38, 425-448, 2006

Lankreijer, H., Janssens, I. A., Buchmann, N., Longdoz, B., Epron, D., and Dore, S.: Measurement of Soil Respiration, in: Fluxes of Carbon, Water and Energy of European Forests, edited by: Valentini, R., Ecological Studies, 163, Springer, Berlin, 37-59, 2003.

Law, B. E., Goldstein, A. H., Anthoni, M., Unsworth, M. H., Panek, J. A., Bauer, M. R., et al.: Carbon dioxide and water vapor exchange by young and old ponderosa pine ecosystems during a dry summer, Tree Physiol., 21, 299-308, 2001.

15 Martin, J. G. and Bolstad, V.: Annual soil respiration in broadleaf forests of northern Wisconsin: influence of moisture and site biological, chemical, and physical characteristics, Biogeochemistry, 73, 149-182, 2005.

Pavelka, M., Acosta, M., Marek, M. V., Kutsch, W., and Janous, D.: Dependence of the $Q_{10}$ values on the depth of the soil temperature measuring point, Plant Soil, 292, 171-179, 2007.

20 Pregitzer, K. S. and Euskirchen, E. S.: Carbon cycling and storage in world forests: biome patterns related to forest age, Glob. Change Biol., 10, 2052-2077, 2004.

Pringle, M. J. and Lark, R. M.: Spatial analysis of model error, illustrated by soil carbon dioxide emissions, Vadose Zone J., 5, 168-183, 2006.

Raich, J. W. and Schlesinger, W. H.: The global carbon-dioxide flux in soil respiration and its relationship to vegetation and climate, Tellus B, 44, 81-99, 1992.

Reichstein, M. and Beer, C.: Soil respiration across scales: the importance of a model-data integration framework for data interpretation, J. Plant Nutr. Soil Sc., 171, 344-354, 2008.

Robertson, G. P., Klingensmith, K. M., Klug, M. J., Paul, E. A., Crum, J. R., and Ellis, B. G.: Soil resources, microbial activity, and primary production across an agricultural ecosystem, Ecol. Appl., 7, 158-170, 1997.

Ryan, M. G. and Law, B. E.: Interpreting, measuring, and modeling soil respiration, Biogeochemistry, 73, 3-27, 2005

Saiz, G., Green, C., Butterbach-Bahl, K., Kiese, R., Avitabile, V., Farrell, E. P.: Seasonal and 9997

spatial variability of soil respiration in four Sitka spruce stands, Plant Soil, $287,161-176$ 2006.

Salimon, C. I., Davidson, E. A., Victoria, R. L., and Melo, A. W. F.: $\mathrm{CO}_{2}$ flux from soil in pastures and forests in southwestern Amazonia, Glob. Change Biol., 10, 833-843, 2004.

5 Schimel, D. S.: Terrestrial ecosystems and the carbon cycle, Glob. Change Biol., 1, 77-91, 1995.

Soe, A. R. B. and Buchmann, N.: Spatial and temporal variations in soil respiration in relation to stand structure and soil parameters in an unmanaged beech forest, Tree Physiol., 25, 1427-1436, 2005.

10 Sotta, E. D., Veldkamp, E., Guimaraes, B. R., Paixao, R. K., Ruivo, M. L. P., and Almeida, S. S.: Landscape and climatic controls on spatial and temporal variation in soil $\mathrm{CO}_{2}$ efflux in an Eastern Amazonian Rainforest, Caxiuana, Brazil, Forest Ecol. Manag., 237, 57-64, 2006.

Stoyan, H., De-Polli, H., Bohm, S., Robertson, G. P., and Paul, E. A.: Spatial heterogeneity of soil respiration and related properties at the plant scale, Plant Soil, 222, 203-214, 2000.

15 Subke, J. A., Inglima, I., and Cotrufo, M. F.: Trends and methodological impacts in soil $\mathrm{CO}_{2}$ efflux partitioning: a metaanalytical review, Glob. Change Biol., 12, 921-943, 2006

Valentini, R.: Fluxes of Carbon, Water and Energy of European Forests, Ecological Studies 163, Springer, Berlin, 2003.

van Miegroet, H., Moore, T., Tewksbury, C. E., and Nicholas, N. S.: Carbon sources and sinks in high-elevation spruce-fir forests of the Southeastern US, Forest Ecol. Manag., 238, 249-260, 2007.

van't Hoff, J. H.: Lectures on Theoretical and Physical Chemistry. Part 1: Chemical Dynamics, Ewald Arnold, London, 1898.

Vogel, J. G., Valentine, D. W., and Ruess, R. W.: Soil and root respiration in mature Alaskan

25 black spruce forests that vary in soil organic matter decomposition rates, Can. J. Forest Res., 35, 161-174, 2005.

Yim, M. H., Joo, S. J., Shutou, K., and Nakane, K.: Spatial variability of soil respiration in a larch plantation: estimation of the number of sampling points required, Forest Ecol. Manag., 175, 585-588, 2003. 
Table 1. Required number of soil respiration measurement points to achieve a precision of $\pm 10, \pm 20$, or $\pm 30 \%$ around full population mean at various confidence levels (80-99\%).

\begin{tabular}{lllll}
\hline Interval [\%] & $99 \%$ & $95 \%$ & $90 \%$ & $80 \%$ \\
\hline \pm 10 & $288 \pm 213$ & $140 \pm 103$ & $92 \pm 68$ & $52 \pm 39$ \\
\pm 20 & $72 \pm 53$ & $35 \pm 26$ & $23 \pm 17$ & $13 \pm 10$ \\
\pm 30 & $32 \pm 24$ & $16 \pm 11$ & $10 \pm 8$ & $6 \pm 4$ \\
\hline
\end{tabular}

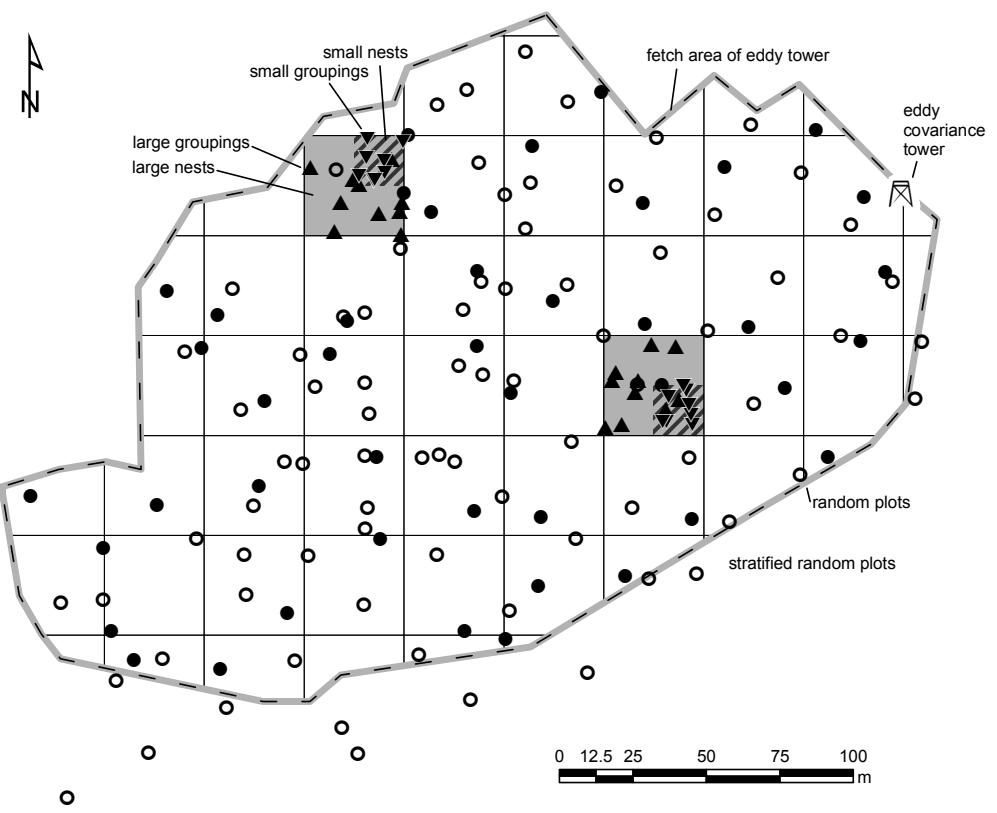

Fig. 1. Distribution of sampling locations in two series. Sampling locations of the random series (81 open circles) are distributed completely random across the site. Sampling locations of the nested series ( 43 dark circles and 36 triangles and $34 \mathrm{~m}$ grid squares) are arranged in a stratified random way in 2 nested groupings: Two of the cells were chosen randomly from the grid. In both, 9 plots are distributed randomly (large groupings). Both cells are further divided into quarters and in one quarter 9 plots are placed at random (small groupings). 


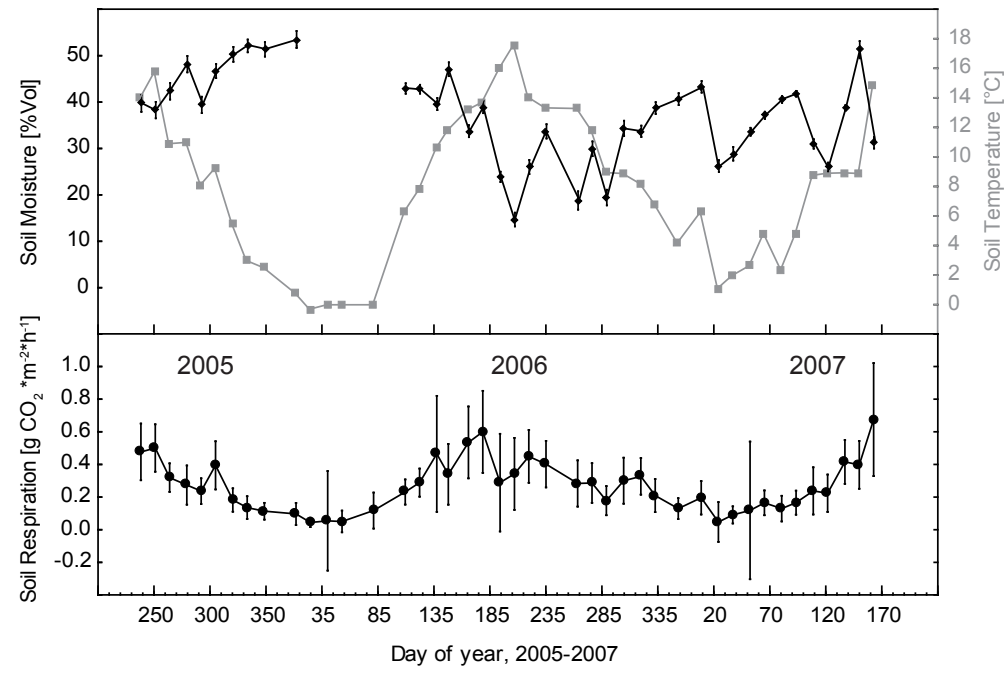

Fig. 2. Soil moisture, soil temperature, and soil respiration during the course of the study. The graphs base on the measurements in the 81 plots of the random series. Vertical bars represent the $95 \%$ confidence interval. The annual cycle is clearly apparent. The soil moisture data gap during winter $2005 / 2006$ is caused by ground frost. Furthermore, the soil respiration measurements show considerable heterogeneity at some of the measurement dates.

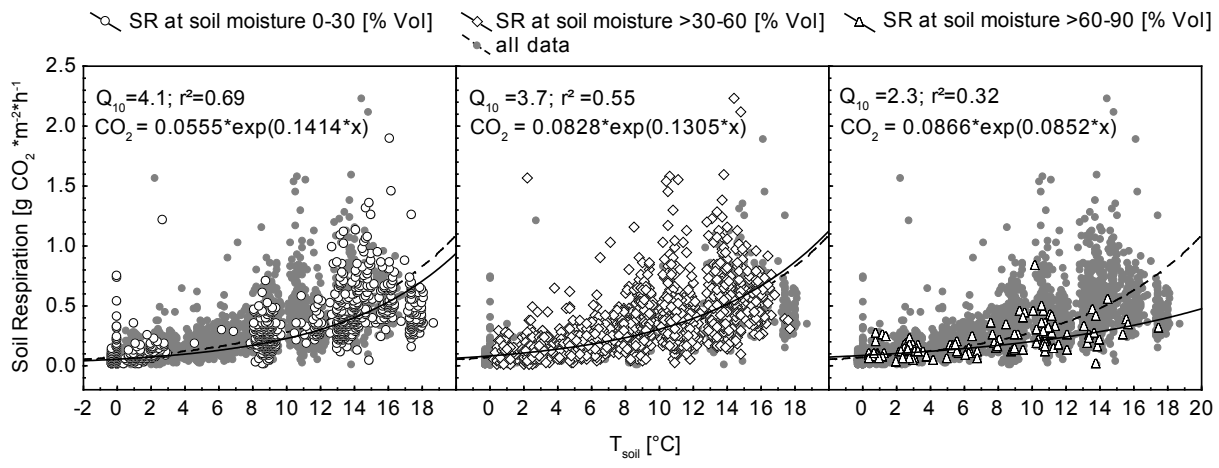

Fig. 3. Relationship between soil temperature and soil respiration. $Q_{10}$ as well as the fit and the parameters of the models vary for different ranges of soil moisture. The $Q_{10}$ for all data is $3.9\left[r^{2}=0.60 ; \mathrm{CO}_{2}=0.0711 \times \exp (0.1365 \times x)\right]$. 

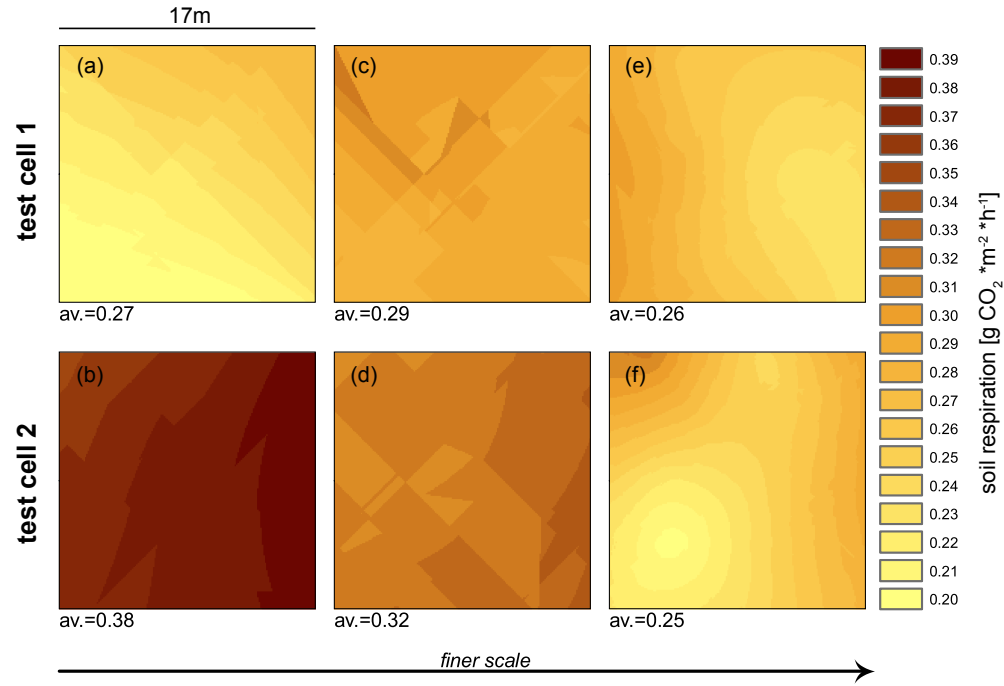

Fig. 4. Comparison of the soil respiration interpolation based on three different sampling densities within two test cells (see methods section for details). The resulting average soil respiration values are given below the panels. Units are $\mathrm{g} \mathrm{CO}_{2} \mathrm{~m}^{-2} \mathrm{~h}^{-1}$. Figure (a) and (b) are kriging results using only data from the stratified random distributed plots, Fig. (c) and (d) represent results using the stratified random plots and data from the large nests, and Fig. (e) and (f) are supplemented with data from the small nests.

$06 / 102005$
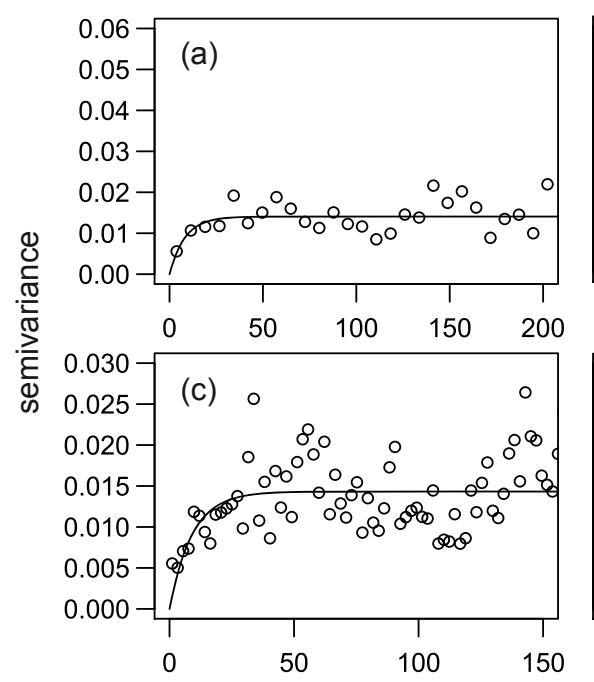

09/30 2005

(b)
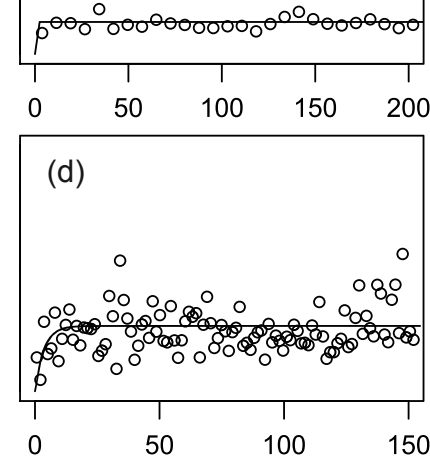

lag distance $[\mathrm{m}]$

Fig. 5. Example semivariograms of soil respiration (a, b): Bin width is $10 \mathrm{~m}$, all possible distances included. (c, d): Bin width=1.5 m, only distances up to $150 \mathrm{~m}$ included. Auto-correlation does only occur at very small distances between plots. 


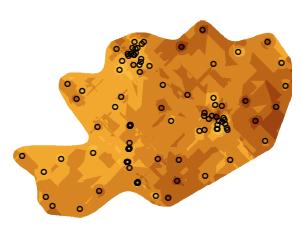

(a) 2005 nested series

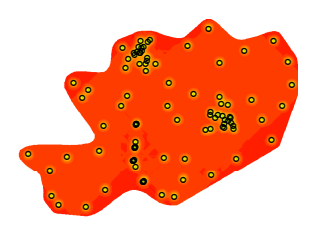

(b) 2005 nested series (PSE)
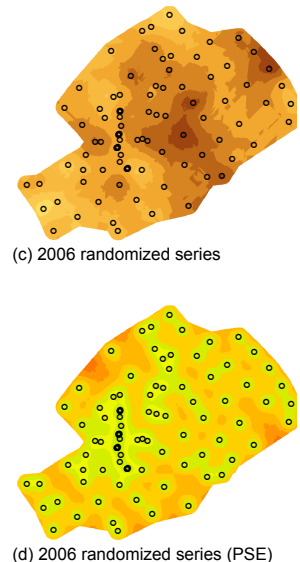

(d) 2006 randomized series (PSE)
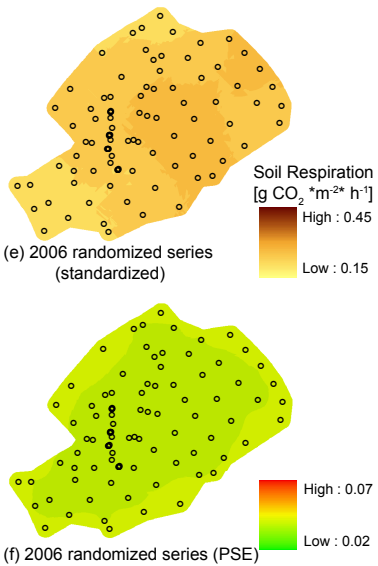

Fig. 6. Interpolated maps of soil respiration measurements of the nested series (a) exhibits a large predicted standard error - PSE (b), whereas the random distribution (c) shows a much smaller PSE (d). The most homogeneous result was achieved by standardizing the randomized soil respiration measurements of 2006 at $11.6^{\circ} \mathrm{C}$ soil temperature and correlative $35.2 \%$ soil moisture (e) possessing little PSE (f). Units are $\mathrm{g} \mathrm{CO}_{2} \mathrm{~m}^{-2} \mathrm{~h}^{-1}$. 